\title{
O GPS USADO NA BATIMETRIA DE GRANDES LAGOS AMAZÔNICOS'.
}

\section{J.A Nunes de MELLO ${ }^{2}$}

RESUMO - É descrita uma metodologia empregando o Global Positioning System, o GPS, no traçado de transectos durante os levantamentos batimétricos realizados em grande lagos amazônicos.

\section{Using GPS in Bethimetric Risings of Amazon big Lakes.}

ABSTRACT - A methodology is shown using Global Positioning System, GPS, in the transects employeers' plans in the risings bathimetric of Amazon big lakes.

Uma grande dificuldade encontrada nos levantamentos batimétricos dos grandes lagos, tem sido os deslocamentos laterais imprevisíveis da embarcação rastreadora, provocado pêlos ventos. $\mathrm{O}$ uso, até hoje considerado como normal, da bússola (magnética ou giroscópica) não conseguia um traçado satisfatório, melhorando com o surgimento do Global Positioning System ou simplesmente GPS. No levantamento batimétrico do Lago do Carão, Arquipélago de Anavilhanas, Amazonas, Brasil, foi empregada a seguinte metodologia:

Num mapa, escala 1:250.000 a partir coordenadas mais próximas do objetivo, são traçadas paralelas com intervalo de um minuto, o que equivale a 1852 metros ou uma milha náutica. Isso é feito tanto para as latitudes e como para as longitudes. Cada reta é marcada com o seu valor em graus e minutos. Feito isso, a gravura é ampliada num aparelho de reprodução (xerox) até o ponto desejado. Está claro que existirá um limite para essa ampliação provocado, inicialmente, pela área de visão da máquina, bem como pela ampliação de defeitos existentes, o que poderá tornar impraticável a utilização da gravura.

De posse da gravura ampliada e já no lago, é iniciado um percurso pôr toda a borda do mesmo, marcando os pontos no GPS, empregando códigos particulares para cada ponto, ao qual chamamos de P.R. (Ponto de Referência). Normalmente o GPS comporta até 200 marcações.

Terminado o levantamento acima, estamos de volta ao local onde iniciamos as marcações. Partindo de um P.R. é marcado o transecto a ser percorrido fazendo-se a varredura das profundidades. O GPS mostrará a distância a ser percorrida, a direção magnética e mostrará ainda a posição real do barco varredor dentro da linha

\footnotetext{
Trabalho Realizado Dentro da Licença para Coleta $n^{0}$ 024/97, Fornecida pelo Instituto Brasileiro do Meio Ambiente e Recursos Naturais - IBAMA para o NUC de Anavilhanas, Rio Negro, Amazonas, Brasil, Processo n002005.000438/97-05.

1 Trabalho Realizado Dentro do PPI-3220 (INPA) - Ecossistemas Fluviais e de Áreas Inundáveis.

2 Coordenação de Pesquisas em Geo-Ciências, Instituto Nacional de Pesquisas da Amazônia, Caixa Postal 487 CEP: 69.083-000, Manaus, Amazonas, Brasil.
} 
do azimute. Caso exista uma variação para a direita ou esquerda, será mostrada, inclusive com o valor do desvio, orientando para a correção. Os intervalos de cada leitura batimétrica poderão ser realizados por cronometragem, ou, o que é mais preciso, pela posição geográfica mostrada no GPS.

Os transectos podem ser orientados nas mais variadas direções, de modo a obter-se um maior número de pontos batimétricos.

A metodologia acima foi testada no grande Lago do Carão, o maior lago do interior de ilha do Arquipélago de Anavilhanas. Dando uma idéia da grandeza deste lago, ele possui $15,5 \mathrm{~km}$ de comprimento por $5,3 \mathrm{~km}$ de largura máxima e 3,89 km de largura média, com uma profundidade média de $13 \mathrm{~m}$, sendo a maior $22 \mathrm{~m}$. Com esta metodologia abolimos a estafante rotina de balizamento das margens com marcos e bandeiras, diminuindo o tamanho do grupo, a duração dos trabalhos de campo e, conseqüentemente, baixamos os custos, além de um maior rigor cientifico no trabalho.

\section{Bibliografia citada}

Magellan, 1996. GPS 3000 XL. Satellite Navigator. User Manual. Magellan System Corporation, $94 \mathrm{p}$.

Hofmann-Wellenhof, B; Lichtenegger, H; Collins, J. 1997. Global Positioning System - Theory and Pratice. Springer Wien New York, 4a. ed, 389p.

Welch, Paul S. 1948. Limnological Methods, McGraw-Hill Book Company, Inc. New York, 381p. 